\title{
Somatografías en los Dubliners de James Joyce
}

\author{
Gabriel WeISZ \\ Universidad Nacional Autónoma de México
}

\begin{abstract}
"Somatografías en los Dubliners de James Joyce" trae a la delantera un recurso para leer algunas literaturas del cuerpo, un mundo narrativo que implica un medio para imaginar y visualizar los cuerpos de los personajes. Los Dubliners nos lleva por un recorrido que nos permite corroborar las representaciones de cambios físicos en cada uno de los individuos en el texto. Esta lectura corporal activa un vínculo íntimo entre lectores y personajes. Una cartografía de los protagonistas no sólo ubica a los personajes en el texto sino que los aproxima a nuestras percepciones.
\end{abstract}

PALABRAS ClAVE: Joyce, cuerpo, somatografía, metamorfismos, metáforas.

"Somatographies in James Joyce's Dubliners brings to the forefront a means to read some of his stories as literatures of the body, a narrative world that involves a vehicle to imagine and visualize the bodies of his characters. Dubliners take us into a journey where one can corroborate the depiction of physical change within each of the individuals in the text. This body-reading prompts an intimate bond between readers and characters. A mapping of the protagonists not only places characters in a text but also brings them close to our perceptions.

KEY WORDS: Joyce, body, somatography, metamorphisms, metaphors.

Las características del cuento corto en Dubliners adoptan un tono muy particular al dedicarse a los relatos corporales. Sabemos que si bien la meta prevaleciente durante esta época de la narrativa del cuento corto tradicional figura como bien dibujada y proyectada, en los Dubliners no sigue este derrotero pues viaja por un curso distinto para adquirir una estructura mucho más libre y casual, adoptando lo que algunos denominan como una estructura metamórfica. Los metamorfismos o cambios físicos antes mencionados me conducen al tema de los relatos corporales. Cooke indica que hay algunas categorías principales si se toman "Clay", "Araby", "Los dos galantes" y "El encuentro" como [símbolos] de la infancia, la juventud y la madurez. Pensamos en esas modificaciones a las que se sujetan los cuerpos al transcurrir el tiempo, una suerte de testimonio textual de cuerpos sujetos a los metamorfismos.

La experiencia que puedo compartir como resultado de la lectura de los Dubliners es un recorrido por diversas literaturas del cuerpo. No uso el término somatografía 
como una tecnología para visualizar el cuerpo en ingeniería. Entendemos por somatografías no sólo las escrituras generadas al describir al cuerpo, sus características, la manera en que el texto muestra una construcción narrativa que da vida a los cuerpos de los personajes, sino también sus topografías o los lugares narrativos destinados a los personajes. Nos percatamos que se trata de describir cuerpos ficticios puesto que aluden a personajes literarios, pero cada autor tiene a su disposición un repertorio de conocimientos sobre los cuerpos y sólo algunos logran que durante la lectura de los textos cada personaje adquiera vida en nuestro imaginario corporal. Seleccionamos algunos relatos para recorrer estas somatografías por lo que iniciamos con la lectura de "Las hermanas". ${ }^{1}$ Nos encontramos ante un escenario de deceso y enfermedad, el reverendo James Flynn ha muerto a sus sesenta y cinco años. El narrador nos anuncia que detecta un fuerte olor de flores en la habitación. La somatografía en estas circunstancias del texto pone de manifiesto que los sentidos van dramatizando la escena, ya que el lugar donde está colocado el ataúd con el cuerpo del reverendo se determina por el perfume que desprenden las flores, y nosotros como lectores contrastamos lo anterior con el hedor que puede despedir el cuerpo muerto durante el proceso de descomposición, aunque Joyce no menciona esto último. A medida que se hacen comentarios sobre el reverendo, se especifica que éste se reía de manera solitaria, por lo cual la gente sospecha que algo extraño le ocurría. Esto permite asomarnos a un pasado, cerca del final, que le confiere al ahora difunto una conducta fuera de sus normas cotidianas. Hay un evento que desordena el cotidiano, se percibe un acontecimiento subjetivo en su mente, no sabemos lo que es pero su manera de actuar refleja algo inusual en la conducta de James Flynn. Su cuerpo ocupa un lugar ajeno porque se conduce de modo distinto, cuando menos imaginamos que él se percibe en otro lugar. Se colocan dos lugares: el subjetivo en Flynn y aquel que percibe el resto de la gente.

En el segundo relato, "El encuentro", el narrador rememora la vida junto a su camarada Joe Dillon. Pero lo más importante parece ser la influencia que ejercen los libros de indios y vaqueros en el imaginario de los jóvenes, así éstos comunican a sus lecturas una naturaleza secreta y prohibida, porque el profesor de Historia, el Padre Butler, sólo busca que sus alumnos limiten sus lecturas a la Historia romana que es el tema de clase. Al irse de pinta el narrador y Joe se topan con Mahony, un anciano que los alcanza por el camino. La somatografía va develando el contraste entre los jóvenes; mientras Joe persigue y lanza piedras contra un gato el narrador se queda atrás. Otros contrastes se manifiestan entre los libros que comenta Mahony, los de Walter Scott y Lord Lytton, que según la opinión del anciano no resultan aptos para jóvenes, por lo que asumimos que se refiere al contenido sexual en estas obras. La manera de posicionar los cuerpos en el ámbito narrativo toma sentido al acentuar el lado físico del juego en el caso de los relatos de vaqueros que Joe presenta a sus amigos y aquellos que menciona Mahony.

"Araby", la tercera narración en Dubliners, arranca con una elocuente personificación de las casas en North Richmond Street. Los edificios se observan uno al otro "con

\footnotetext{
${ }^{1}$ Todas las traducciones son de mi responsabilidad.
} 
rostros imperturbables" (15). Cuando el narrador compara su cuerpo con un arpa y las palabras y gestos de su amada lo recorren pulsando sus cuerdas, cobra significado el situar un punto de vista entre cuerpo y objeto que incrementa las intensidades sensoriales de ese momento. Estas escrituras corporales pasan de la personificación arquitectónica al cuerpo del narrador, metaforizado como instrumento musical. A continuación la amada es descrita al momento en que la lámpara de una casa cercana ilumina su cabellera; el juego de luces sobre la mujer imprime un lado pictórico a la escena. Se consigue una somatografía plástica, que de paso visualizamos como un recurso para aumentar el impacto de representación. La lectora construye sus expectativas a partir de que el jovencito promete visitar un bazar y con ello conseguir algo para su amada. El enamorado depende de la llegada de su tío, quien le dará dinero para tomar un tren que lo lleve al bazar de Araby, un nombre que sugiere la carga exótica de Oriente, pero el hombre llega tarde. Cuando el joven toma el tren, éste deja la estación con lentitud, lo cual agrava la desesperación del protagonista, quien quiere alcanzar su destino antes de que todo cierre en el bazar. Finalmente llega al lugar anhelado, encuentra todos los puestos cerrados menos uno donde se venden objetos de porcelana. La vendedora está coqueteando con unos hombres, y le pregunta desganada al joven si quiere adquirir algo pero él responde tímidamente que no. Nuevamente hay un proceso de personificación en el que los jarrones se perciben por el narrador como guardianes orientales vigilando la entrada del puesto. La reminiscencia del lugar exótico nos regresa a la legendaria "Araby". Definitivamente representa una topografía del texto lejano y misterioso. La culminación emocional del personaje alcanza el nivel de saturación cuando es invadido por una mezcla de rabia y frustración por no haber logrado su cometido, o sea la entrega del posible regalo que ha prometido, y en cambio regresar con las manos vacías. En este caso sentidos y emociones convergen en un lugar que contrasta con los "rostros imperturbables" de las casas en North Richmond Street y una promesa del Oriente de "Araby" que resulta en una empresa fallida todavía mayor a la de estar esperando al tío, quien olvida que ayudaría al narrador en su ansiada visita al bazar.

Otro espacio narrativo corresponde a "Eveline". El personaje está en esa situación que vivimos cuando pensamos ver el entorno de nuestro cotidiano por última vez; la somatografía de ese lugar que recorre nuestra memoria ubica al cuerpo en esa inmanencia deleuziana, o sea ese existir o permanecer adentro, en cuyo interior se generan condiciones para circunscribir el mundo propio del personaje. El olor que despide la tela polvosa de algodón, los objetos tan bien conocidos por ella del entorno doméstico, que había limpiado tantas veces, ahora la invaden con una sensación de separación. Dejará todo, incluyendo la amenaza continua de un padre violento, para reunirse con su amado. La somatografía de la violencia entra en juego en el momento en que la protagonista sufre cada vez más amenazas del padre, y ahora nadie la podrá defender. Con esto se define una serie de condiciones físicas que le brindan un significado inmanente a la narrativa. El elemento principal en esta lectura deriva del evento violento, o de su posibilidad, por lo que tenemos que explorar las consecuencias de esas condiciones que generan el ambiente de agresividad. ¿Escapará entonces con Frank a Buenos Aires para 
así terminar con su actual forma de vida? Aquí surge el punto del relato donde el sentido de una topografía cobra valor, el cotidiano del personaje se transforma en su cárcel, y abandonar el lugar es imposible; el mundo propio de esta mujer constituye su encierro. Su topografía queda reducida al claustrofóbico espacio de la angustia.

Dubliners devela otra instancia de construcción narrativa en "Después de la carrera". El motivo al inicio del relato gira en torno a los automóviles, y aquí es el auto que resulta personificado como una bestia, y "la maquinaria de nervios humanos" (26) es la que busca responder al animal azul. Estos aspectos me hacen recordar toda la reflexión sobre el devenir como lo ha descrito Deleuze, que ocurre entre un sujeto u otro. "La literatura es inseparable del devenir: al escribir nos convertimos en mujeres, devenimos en animales o vegetales, devenimos en moléculas hasta tornarnos invisibles" (11). Cuando un grupo de amigos se pasea en auto, Joyce presenta en "Después de la carrera" una frontera entre 'la maquinaria humana' y la personificación del auto como animal azul. Durante la lectura se respira un ambiente festivo y excitante entre la velocidad del automóvil y la velocidad emocional del alcohol y de las pérdidas que sufren dos de los amigos, Farley y Jimmy, durante el juego de cartas, pero que ellos no quieren recordar en ese momento para no estropear la diversión; hay que perderse en el delirio del automóvil, de la bebida y del juego.

"Dos galantes" narra la historia de Lenehan y Corley. La somatografía se sugiere por la presencia de Corley, un personaje visiblemente corpulento y quien parece desconocer o abusar de su espacio corporal, pues de manera muy insolente ocupa toda la banqueta al charlar y caminar en compañía de su amigo, quien continuamente debe caminar por la calle. La descripción de Corley con la piel "aceitosa" y sudorosa imparte la idea de volumen y produce una cierta repugnancia. "Su cabeza grande globular y aceitosa; sudaba en todos los climas..." (30). Con todo, Lenehan busca convertirse en Corley porque éste tiene una cita con una mujer. A lo cual Corley le replica: “¿Estás tratando de ocupar mi lugar?" (33). El cuerpo del otro se convierte en vehículo de experiencias vicarias. Corley se aleja con el porte del conquistador por su manera de caminar y por sus actitudes corporales. La mujer se construye como calca de la corpulencia de Corley.

En el relato su apariencia es la de un ser saludable, con mejillas rosadas, es de corta estatura pero musculosa. A medida que la narración se desarrolla nos percatamos de la enorme dependencia que tiene Lenehan de Corley y cómo su estado anímico cambia radicalmente cuando ya no está en compañía de su amigo. Todo lo que acontece a Corley lo afectará, vive a través de las experiencias de éste como si viajara en el cuerpo de Corley: "Sufría todo el dolor y emoción de la situación de su amigo como si fueran las propias" (36). Sobresale la importancia de vivir la existencia de alguien más en un cuerpo que hace suyo. La somatografía constata los traslados de un cuerpo al otro y las consecuencias que trae consigo una relación de un sujeto dominante y otro sometido para definir la identidad de uno y otro personajes y el lugar que ocupan, no sólo en el episodio de la caminata por la acera, sino también por la existencia de cada cual. Hay una evidente relación de poder: mientras que Lenehan quiere saber todo sobre su amigo, éste, en cambio, le muestra una total indiferencia. 
"Casa de huéspedes" da inicio con la Sra. Mooney, dueña de una carnicería. Con esta introducción se prosigue con la historia del joven huésped interesado en Polly, la hija de la Sra. Mooney. El tema de la carnicería se extiende para comparar la profesión de la dueña con asuntos de su conducta, ya que "soluciona problemas morales como un cuchillo de carnicero con la carne" (39). El enunciado anterior alude a la manera en que la Sra. Mooney pretende 'resolver' la relación sexual entre su hija y el joven Doran. Manda llamar a Doran, éste se encuentra tan angustiado ante la perspectiva de la entrevista con la carnicera que es incapaz de rasurarse. Constatamos un relato corporal que revela la tensión: el tremor de sus manos le impide afeitarse. Los síntomas que afectan su estado anímico no sólo quedan manifiestos por su impedimento, sino también por una barba rojiza en sus mejillas y el hecho que sus anteojos se empañan continuamente. Su imaginario está poblado por visiones de un matrimonio obligado y las convenciones sociales como parte de verdaderos obstáculos emocionales. El contraste con el relato corporal de Polly es que el personaje se define como una persona perdida en un sueño diurno, con las expectativas y visiones de un futuro. Algo quiere recordar, pero sólo lo consigue cuando su madre le anuncia que el Sr. Doran quiere decirle algo. La reflexión que aplicamos sobre ésta y otras narraciones es que los relatos corporales son moldeados por una serie de reglas y obligaciones sociales que afectan el perfil e identidad de cada personaje de modo distinto, pues las relaciones de poder no son las mismas para Polly, quien es apoyada por el dominio doméstico gobernado por la carnicera, y el lugar bastante más vulnerable que ocupa el joven Doran.

"Barro", otra de las historias del texto, se centra en María. Imaginemos que podemos dividir algunos relatos en una mezcla de introspección y exposición, ambos conceptos vinculados a una manera de mirar. Cuando ella se dispone acudir a la iglesia después de su trabajo, se contempla en el espejo y describe un cuerpo diminuto "que tantas veces había adornado" (65). Aquí no sólo se ve expuesta en el espejo sino recuerda su cuerpo infantil en un proceso de introspección. Mediante este recurso podemos apreciar cómo el personaje aparece ante los demás y cómo se visualiza a sí misma. Opera una narrativa externa de 'exposición' y su contraste introspectivo. Regresando al tema del devenir, María cambia de un atuendo que la define como parte de la servidumbre, a una mujer que acude a la iglesia con una indumentaria muy elegante.

La temática que recorre nuestra lectura toma como referente inicial el concepto de estructura metamórfica por los cambios físicos generados en cada relato que hemos mencionado, y el razonamiento tras el empleo deleuziano del devenir conduce a una forma de literatura de vida y la inmanencia como aspecto que detecta cambios internos.

Todo este conjunto de ideas desemboca en las somatografías que no sólo contemplan las escrituras generadas al describir al cuerpo, sus características en cada relato de los Dubliners, sino también la manera en que el texto muestra una construcción narrativa que ubica los cuerpos en diversas topografías o lugares corporales. En definitiva las somatografías nos enseñan a leer los cuerpos de los personajes en el universo narrativo. 
Obras citadas

Cooke, M. G. "From Comedy to Terror: On Dubliners and the Development of Tone and Structure in The Modern Short Story". The Massachusetts Review. Web. $<$ http://www.jstor.org/stable/25087714>.

Deleuze, Gilles. "La literature et la vie". Critique et Clinique. París: Les Éditions de Minuit, 1993. Impreso.

JoYCE, James. Dubliners. Nueva York: Dover Publications, 1991. 